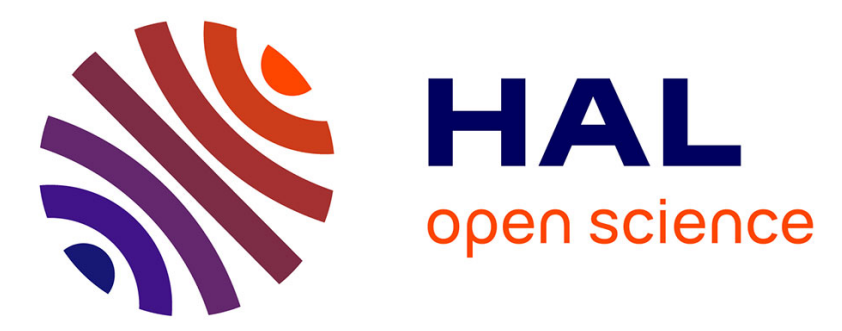

\title{
Rapid assessment of estrogenic compounds by CXCL-test illustrated by the screening of the UV-filter derivative benzophenones.
}

Denis Habauzit, Catherine Martin, Gwenneg Kerdivel, Farzad Pakdel

\section{- To cite this version:}

Denis Habauzit, Catherine Martin, Gwenneg Kerdivel, Farzad Pakdel. Rapid assessment of estrogenic compounds by CXCL-test illustrated by the screening of the UV-filter derivative benzophenones.. Chemosphere, 2017, 173, pp.253-260. 10.1016/j.chemosphere.2017.01.037 . hal-01477205

HAL Id: hal-01477205

https://hal-univ-rennes1.archives-ouvertes.fr/hal-01477205

Submitted on 27 Mar 2017

HAL is a multi-disciplinary open access archive for the deposit and dissemination of scientific research documents, whether they are published or not. The documents may come from teaching and research institutions in France or abroad, or from public or private research centers.
L'archive ouverte pluridisciplinaire $\mathbf{H A L}$, est destinée au dépôt et à la diffusion de documents scientifiques de niveau recherche, publiés ou non, émanant des établissements d'enseignement et de recherche français ou étrangers, des laboratoires publics ou privés. 
1 Rapid assessment of estrogenic compounds by CXCL-test illustrated by the

2 screening of the UV-filter derivative Benzophenones

3 Denis Habauzit ${ }^{*}$, Catherine Martin, Gwenneg Kerdivel, Farzad Pakdel

4 Institut de Recherche en Santé - Environnement - Travail (IRSET), Inserm U1085, TREC Team, University of

5 Rennes 1, Rennes, France

6

7

*Corresponding author:

8

Dr. Denis HABAUZIT

9

IRSET, Inserm U1085, University of Rennes 1, 35000 Rennes cedex, France.

Phone: +33-2 23235132

11

Fax: +33-2 23236794

12

E-mail: denis.habauzit@univ-rennes1.fr

13

farzad.pakdel@univ-rennes1.fr

14

15 
CXCL-test is a method that uses the estrogen-dependent secretion of the natural endogenous chemokine CXCL12 to evaluate the estrogenic activity of molecules. CXCL12 chemokine is involved in the estrogen dependent proliferation of breast cancer cells. Its measure is an indicator of cell proliferation and is used as an alternative test to classical proliferation test.

Here we aimed to optimize this test, first to increase the number of tested molecules in a single assay and then to decrease the number of intermediate steps. The optimized CXCL-test was finally used for the evaluation of the estrogenic potency of emerging chemical pollutants: the UV filter benzophenones (BPs). The effect of BPs on CXCL12 secretion was also validated by real time quantitative RT-PCR.

The optimized CXCL-test allowed a fast and direct assessment of estrogenic potency of molecules. The estrogenic activities of benzophenones were characterized and divided in two groups. The first one contains weak estrogenic compounds (BP, BP1, BP2, BP3, 234BP and 2344'BP). The second one contains medium estrogenic compounds (4BP, 44’BP, BP8, THB).

Highlights

- CXCL-test optimization allows the assessment of several estrogenic chemicals in a single assay

- Utilization of CXCL-test to measure estrogenic activity of benzophenones

- Benzophenones have estrogenic activity in the $\mu \mathrm{M}$ range

\section{Keywords}




\section{Introduction}

38

Human activities, due to industrialization and to drugs consumption, have led to the increase of diverse chemical releases in environment, especially in surface water. This increase is partially due to the incomplete elimination of the contaminants in waste water treatment plan. Some of these chemicals evidenced unpredicted endocrine disrupting activities. The main difficulty in this research area is that the disruption could occur in large biological tissues, functions, pathways or proteins (Kerdivel et al., 2013a; Yoon et al., 2014). Therefore the assessment of endocrine disrupting activity for many compounds was always performed a posteriori either after several years of the use of compounds or because of an evidence of a health effect, such as the use of Diethylstilbestrol or Bisphenol A. Moreover, the assessment is sometimes performed after the detection of a high concentration of several compounds in environment linked with adverse effects in wildlife evidenced through morpho-anatomical modifications or expression of feminine protein marker in male fish. Since, many comity or regulations have aimed to develop early evaluation of the new chemical such as EDSTAC (now EDSP) and Reach program. Several methods have been established over the last 3 decades in order to assess endocrine disrupting chemical (EDC) activities, especially estrogenic activity (Leusch, 2008; Scholz et al., 2013). These methods specifically target several critical points that have been identified in fundamental studies in the endocrine function such as development of uterus (Isenhower et al., 1986), estrogen-induced proliferation of cell lines (Soto et al., 1995), expression of estrogen-regulated genes (vitellogenin) (Flouriot et al., 1995) or molecular interaction with transcription factors (Habauzit et al., 2007). But the evaluation of the estrogenic activity of a molecule raises several questions about the relevance of the target, the considered material (organ, tissue, cells or molecules), and the analysis time and cost.

CXCL12 is a cytokine coupled with two G protein coupled receptors (CXCR4 and CXCR7) that is implicated in the proliferation and migration of breast cancer cells (Boudot et al., 2011). E2-induced CXCL12 expression and its impact on cell proliferation has then been illustrated by our team and others (Boudot et al., 2011; Glace et al., 2009; Hall and Korach, 2003; Pattarozzi et al., 2008). Moreover, we have demonstrated that CXCL12 secretion is an early indicator of estrogen-dependent proliferation of breast cancer cells (MCF7 and T47D). The knowledge of estrogen-dependent regulation of this cytokine led to the development of a fast test for the assessment of estrogenic effect of molecules (Habauzit et al., 2010). By using CXCL12 secretion for EDC- 
evaluation, Hall and Korach demonstrated that some EDCs also induce growth of ovarian cancer cells through the estrogen receptor (ER)-dependent induction of CXCL12 expression (Hall and Korach, 2013). CXCL-test is faster (14 hours) than the classical proliferation test (5-7 days) and sensitive enough for the assessment of both strong and weak estrogenic compounds.

Even if a lot of methods for the evaluation and the quantification of EDCs exist, few tests are using natural endogenous genes expression with a low detection limit for the evaluation of the proliferative ability of molecules. Moreover, due to the diversity of estrogenic compounds' actions and pathways, numerous methods have to be developed for the entire evaluation of the molecule action. For that reason, we aimed to ameliorate and optimize the CXCL-test by scaling it up to 96 wells plate and by reducing intermediate steps. To validate these optimizations and illustrate their relevance for risk assessment, we assessed a new EDC family with estrogen-like activity, the benzophenones. They are used in several cosmetic products and they possess ultraviolet (UV) filter activities. Because of their lipophilic properties, they penetrate easily in bodies and can be found in human fluid such as urine (Vela-Soria et al., 2014), women milk (Rodríguez-Gómez et al., 2014). The diversity of benzophenone's use makes that large amount of these compounds are found in the waste water treatment plant and constitute a risk for wildlife (Jurado et al., 2014). As the treatment plant eliminates only partially these compounds, they are found to high concentration (up to $\mathrm{mg} / \mathrm{L}$ ) in rivers all over the world (Tsui et al., 2014) and also in sediment (Gago-Ferrero et al., 2011). There are increasing concerns on the potential endocrine disrupting effect of these molecules. In this study, we show that among the 10 compounds evaluated, all have an estrogenic activity. 


\section{Material and methods}

87

\subsection{Materials}

Actinomycin D, benzophenone (BP), bovin serum albumin (BSA), 17- $\beta$-estradiol (E2), 17- $\alpha$-ethynylestradiol (EE2), 2,4-dihydroxy-benzophenone (BP1), genistein (Gen), 2,2',4,4'- tetrahydroxy-benzophenone (BP2), 2-hydroxy-4-methoxy-benzophenone (BP3), 4-hydroxybenzophenone (4BP), 4,4'-dihydroxybenzophenone (44'BP), 2,3,4-trihydroxy-benzophenone (234BP), 2,3,4,4'-tetrahydroxy-benzophenone (2344'BP), 2,2'-hydroxy-4-methoxy-benzophenone 6 (BP8), 2,4,4'-trihydroxy-benzophenone (THB), progesterone (P4) and testosterone $(\mathrm{T})$ were acquired from Sigma-Aldrich Co.

\subsection{Cell Culture and treatments}

T47D cells, obtained from ATCC, were routinely maintained in RPMI (Invitrogen, Life technologies, Saint Aubin, France) supplemented with 10\% fetal bovine serum, FBS (Biowest, Nuaillé, France) and antibiotics containing penicillin, streptomycin and Amphotericin (Invitrogen, Life technologies, Saint Aubin, France) at $37^{\circ} \mathrm{C}$ in $5 \% \mathrm{CO} 2$. Before treatment cells were plated in DMEM phenol red-free (Gibco, Life technologies, Saint Aubin, France) containing 5\% dextran treated charcoal-stripped FBS (dsFBS) provided by Biowest (Biowest, Nuaillé, France). For treatment, $0.1 \%$ ethanol (control) and each compound (E2, EE2, Gen, BP, BP1, BP2, BP3, 4BP, 44'BP, 234BP, 2344'BP, BP8, THB, P4 and T) was diluted with DMEM phenol red-free containing 5\% dsFBS at the appropriate concentration.

\subsection{ELISA assay}

Cells were cultured in 96-well plates containing either $4.10^{4}$ cells/well in DMEM phenol red-free medium containing $5 \%$ of dsFBS. After 24 hours, medium was replaced and cells were then treated with DMEM phenol red free medium with 5\% of dsFBS containing the tested molecules during 14 hours. Then, $60 \mu 1$ of supernatant were equally diluted with PBS containing 1\% BSA. The quantification of CXCL12 secretion was then performed by ELISA (Quantitine kit; R\&D Systems, Mineapolis, MN, USA). 

dilution step, several cell density per well were tested. Between 2500 to 40000 cells per well were evaluated.

113 Finally Ten thousands cells per well, cultured in 96-well plate, were chosen for the evaluation of BP estrogenic potency. The medium was then replaced with $100 \mu \mathrm{l}$ of DMEM phenol red-free medium containing 5\% of dsFBS during 24 hours. Then $100 \mu 1$ of DMEM phenol red free containing treatment were added. After 14 hours of incubation, $100 \mu$ of the supernatant was directly analyzed by ELISA. For each experiment, a standard curve was generated. ELISA was revealed with the CXCL12 Duoset Elisa kit from R\&D Systems. The absorbance at 450 and $570 \mathrm{~nm}$ was obtained by using a 96-well iMARK Absorbance microplate reader (Biorad, Life Science, Marnes-la-coquette, France).

\subsection{RT-PCR assays} T47D cells were seeded in 6 well-plate in a density at $1.10^{5}$ cells/well in DMEM phenol-red free medium containing $5 \%$ of dsFBS. After 24 hours, cells were treated with $10^{-6} \mathrm{M}$ of each BP and $10^{-8} \mathrm{M}$ of E2 and $0.1 \%$ ethanol as control during 24 hours. For each treatment, total RNA was extracted with Trizol reagent (Invitrogen) according to supplier's instructions. RNAs were then reverse transcribed in cDNA by MMLV (Promega, Charbonnère, France) using random hexamers (Promega). Quantitative RT-PCR were performed on BioRad MyiQ with iQ Sybr Green Supermix (BioRad, Hercules, CA, USA) using primers for CXCL12, Rev: GCCTCCATGGCATACATAGG, Fwd: CTCCTGGGGATGTGTAATGG and for GAPDH as control, Rev: GGGCATCCTGGGCTACACTG, Fwd: GAGGTCCACCACCCTGTTGC. (http://marne.u707.jussieu.fr/biostatgv/?module=tests). Differences were considered as significant if $\mathrm{p}$ value < 0.05 . 


\section{RESULT}

135

\subsection{Effect of classical estrogenic compounds on the secretion of CXCL12 in 96 well-plate}

In previously published method, 24 well-plates were used. By scaling up this method to 96 well-plates, we aimed to screen more conditions during the same experiment. We therefore evaluate the effect of classical estrogenic compounds such as the strong agonist 17- $\alpha$-ethynyl estradiol (EE2), the natural hormone 17- $\beta$ estradiol (E2) and the weak agonist genistein (Gen). Each compound induced an increase of the secretion of CXCL12 when compared to the control ethanol (Fig. 1). E2 and EE2 induced up to 5 to 6-fold increase of CXCL12 secretion. A decrease of the CXCL12 secretion was nevertheless observed for concentration of EE2 up to $10^{-8} \mathrm{M}$ as previously published (Habauzit et al., 2010). Gen also increased the CXCL12 secretion. Consistently with its well described weak agonistic potency, Gen only induced effect at doses higher than $10^{-8}$ M. The EC50 of each curves was determined and was respectively of $3.15 \times 10^{-13} \mathrm{M}$ for E2, $2.14 \times 10^{-14} \mathrm{M}$ for EE2 and $7.17 \times 10^{-8} \mathrm{M}$ for Gen (Table 1). The first effects of molecules on CXCL12 secretion were observed at $10^{-14}$ M E2 (3 fold increase) and $5 \times 10^{-16} \mathrm{M}$ of EE2 (2-fold increase).

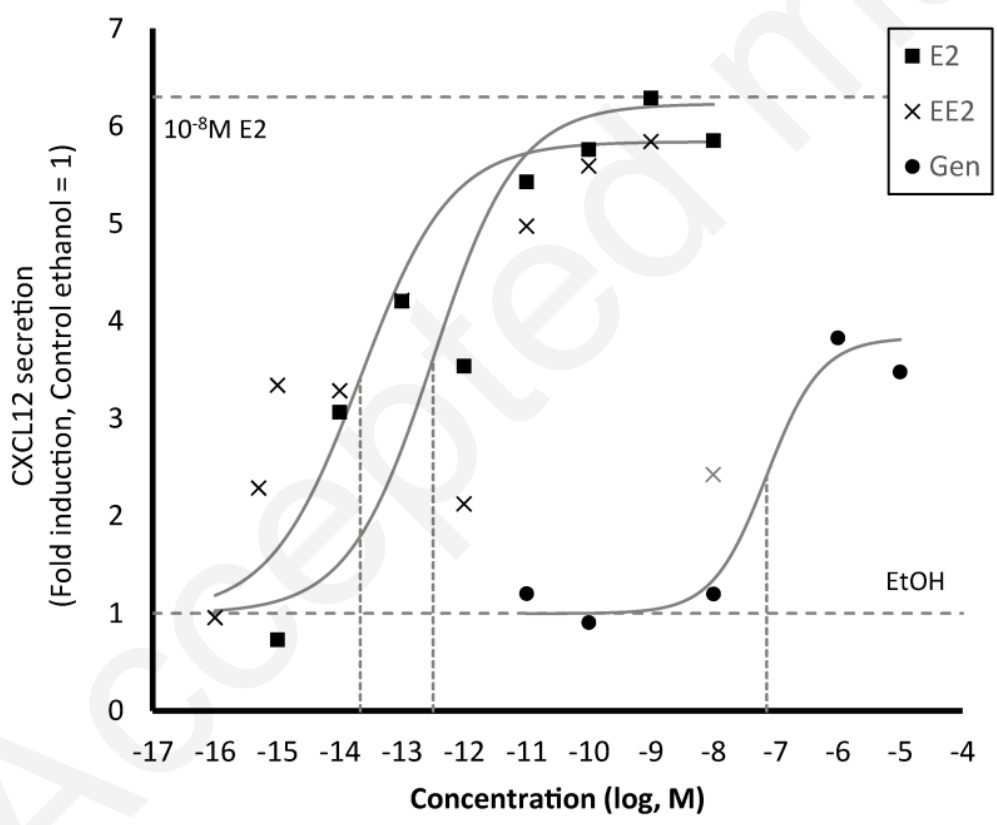

Fig. 1: CXCL12 secretion under classical estrogenic compounds stimulation in 96 well plate.

3.2. Determination of the optimum number of cells for the ELISA detection without intermediate steps 
A supernatant dilution step was previously performed to keep the ELISA signal in the linear range of the calibration curve. In this second step of the method optimization, the intermediary dilution of the supernatant in PBS 1\% BSA was removed by decreasing cell number. Different cell density from 2500 cells/well to 40000 cell/well (Fig. 2) were cultured on 96-well plates. Cells were exposed to $10^{-8} \mathrm{M}$ E2 or ethanol, as control. The secretion of CXCL12 in $100 \mu \mathrm{l}$ of supernatant was monitored and represented as a fold change between exposed to ethanol and E2 (Fig. 2). The $2 \times 10^{4}$ and $4 \times 10^{4}$ cell numbers permitted to visualize the E2 effect with fold change of 2.4 compared to the ethanol control. The presence of an equivalent fold change in these two cellular densities raises the question of the signal saturation, even if for $2 \times 10^{4}$ cells per well, the ELISA is performed in the linear range of the calibration curve. Therefore $1 \times 10^{4}$ cells per well were preferred. With a fold change of 1.9, this cell number allowed significantly to evaluate the estrogenic potency of compounds without saturation signal risk.

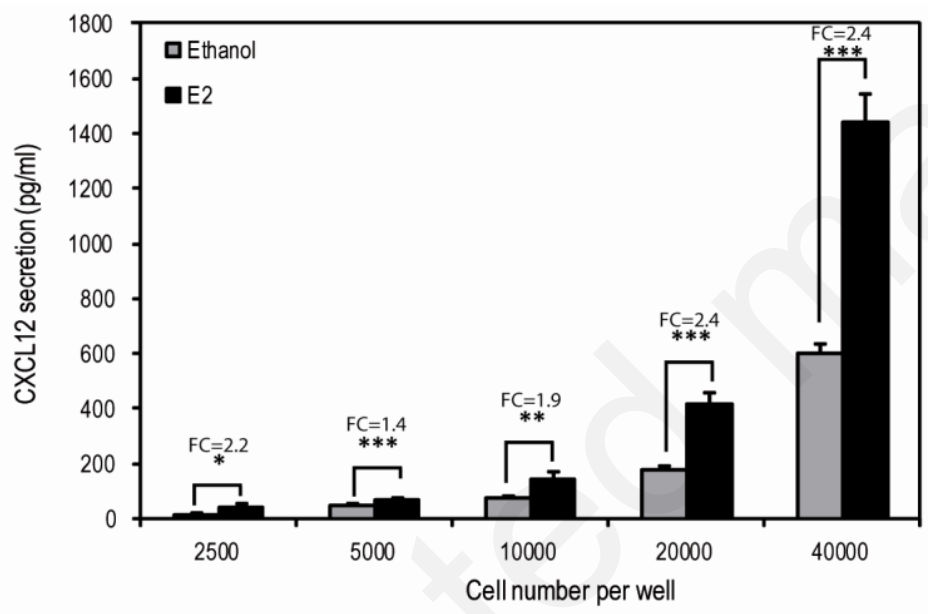

Fig. 2: CXCL12 secretion depending upon the cell number coated in the 96 well plate and without PBS/BSA intermediary dilution. $(* \mathbf{P}<0.05, * * \mathbf{P}<0.01, * * * \mathbf{P}<0.005)$

\subsection{Specificity of the estrogenic sensitivity of the CXCL12 secretion}

Two well-known endocrine compounds with non-estrogenic activity were tested on the ability to induce the CXCL12 secretion. These two compounds were the male hormone testosterone (T) and the women menstrual and pregnancy hormone progesterone (P4). The stimulation by a dose effect of these two compounds did not 

estrogenic stimulation.
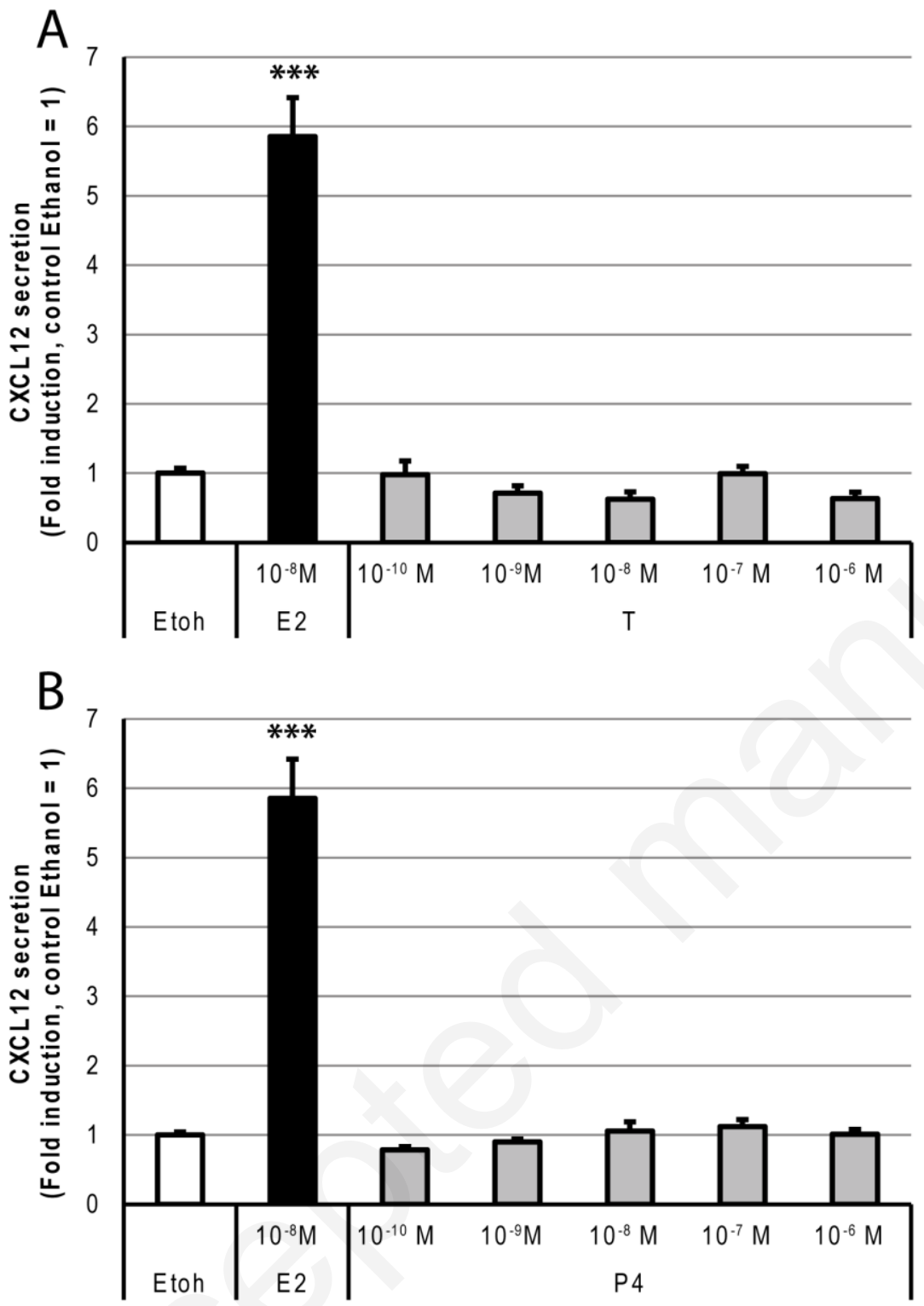

Fig. 3: Assessment of the estrogenic properties of dose effect of A) testosterone (T) and B) progesterone (P4) by CXCL-test

3.4. Use of the optimized CXCL-test for the assessment of estrogenic potency of Benzophenones

According to our developed ELISA method, all 10 tested benzophenones exhibit estrogenic properties compounds can be delineated. The first one contains 6 compounds (BP, BP1, BP2, BP3, 234BP and 2344'BP) 

that have a weak estrogenic activity with EC50 near $10^{-5} \mathrm{M}$ (table 1 ). The only active dose is $10^{-5} \mathrm{M}$ and the maximum response is lesser than $70 \%$ of E2 effect. The 4 last compounds (4BP, $44^{\prime} \mathrm{BP}$, BP8 and THB) have medium estrogenic properties with active concentration from $10^{-6} \mathrm{M}$ and the maximum response is between $80 \%$ and $110 \%$ of E2 effect. The most powerful estrogenic compounds are 44'BP (near 100\% of E2 effect) and BP8 $182(110 \%$ of E2 effect).

\begin{tabular}{cc}
\hline Compounds & EC50 (M) \\
\hline E2 & $3.15 \times 10^{-13}$ \\
\hline EE2 & $2.14 \times 10^{-14}$ \\
\hline Gen & $7.18 \times 10^{-8}$ \\
\hline BP & $1.09 \times 10^{-5}$ \\
\hline BP1 & $9.46 \times 10^{-6}$ \\
\hline BP2 & $8.29 \times 10^{-6}$ \\
\hline BP3 & $9.93 \times 10^{-6}$ \\
\hline 4BP & $9.45 \times 10^{-7}$ \\
\hline 44'BP & $6.7 \times 10^{-7}$ \\
\hline 234 BP & $7 \times 10^{-6}$ \\
\hline $2344^{\prime}$ BP & $8.42 \times 10^{-6}$ \\
\hline BP8 & $1.5 \times 10^{-6}$ \\
\hline THB & $5.24 \times 10^{-7}$ \\
\hline
\end{tabular}

Table 1: EC50 of each compound used in the evaluation. 

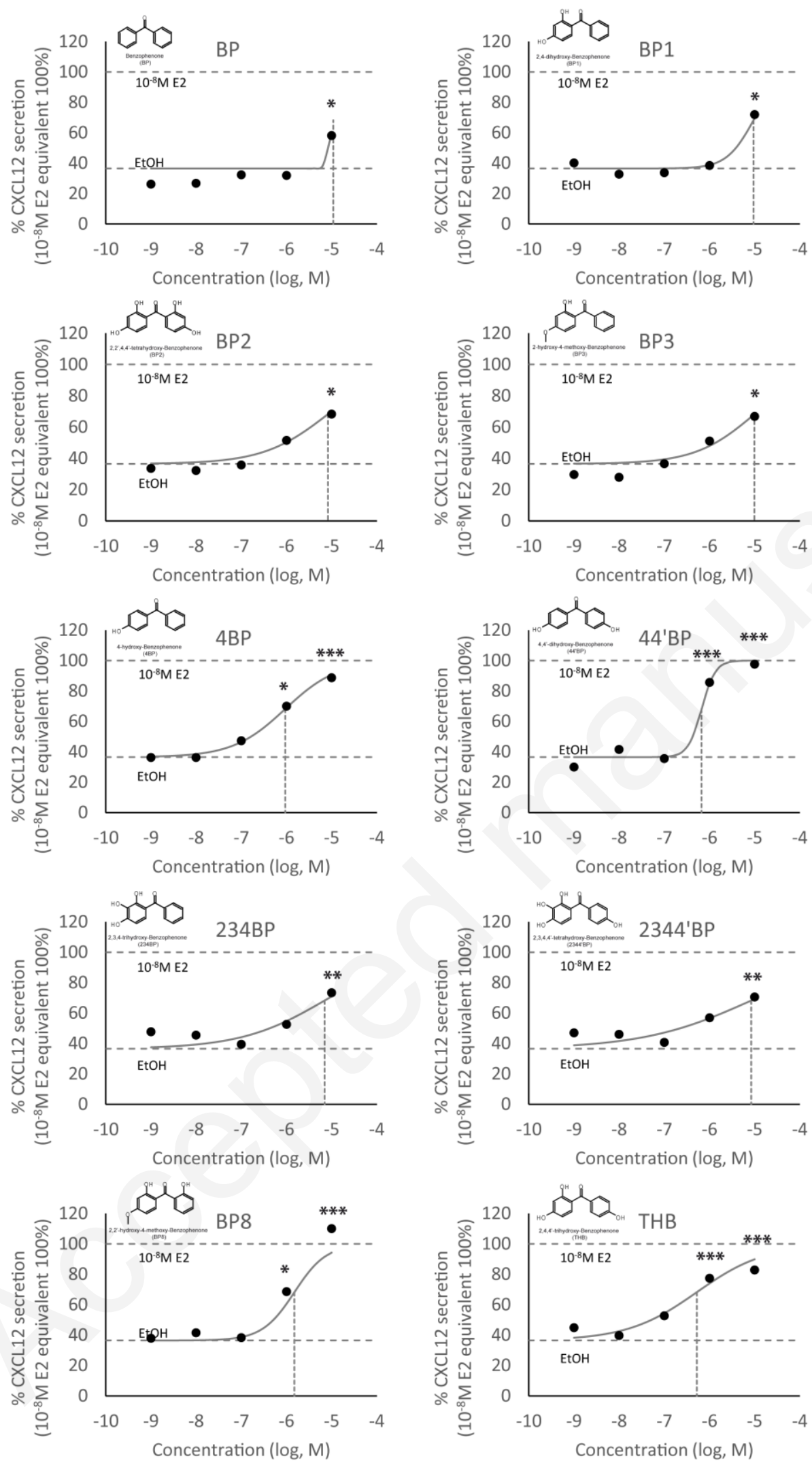

Fig. 4: Assessment of estrogenic properties of different doses of benzophenones (BP, BP1, BP2, BP3, 4BP, 
3.4. Validation of CXCL-test by quantitative PCR

To confirm that stimulation of CXCL12 secretion by BPs is only due to the stimulation of gene expression and not to a transient increase of CXCL12 protein release by action on exocytose, RT-qPCR method was also used. After 24 hours of $10^{-6} \mathrm{M}$ BP treatments, T47D RNA were extracted and then analyzed by qPCR. As shown in Fig. 5A, CXCL12 mRNA obtained after 24 hours of treatment correlated very well with CXCL12 secretion obtained after 14 hours of treatment. The Pearson correlation is $84.15 \%$ with a $p<0.001$. Of note is that at $10^{-6} \mathrm{M}, \mathrm{BP}$ molecule did not show estrogenic activity in both assays while 4BP and BP8 were among the most powerful estrogenic compounds. The differences observed between qPCR and ELISA approaches are likely due to the treatment time as well as the sensitivity of the method. CXCL12 gene transcriptional activity, T47D cells were treated with different doses of BPs, in presence of an inhibitor of the transcription, the actinomycine D. As shown in Fig. 5B, Actinomycin D inhibited the BPdependent CXCL12 secretion for both E2 and BP molecules at their effective doses $\left(10^{-6} \mathrm{M}\right.$ or $\left.10^{-5} \mathrm{M}\right)$. No transcriptional independent release of CXCL12 was observed and no significant differences between control ethanol and BP treatments were observed. The BP-dependent CXCL12 secretion is therefore due to the estrogenic effect of molecules and not of an increase in CXCL12 release in cell supernatant. 
A

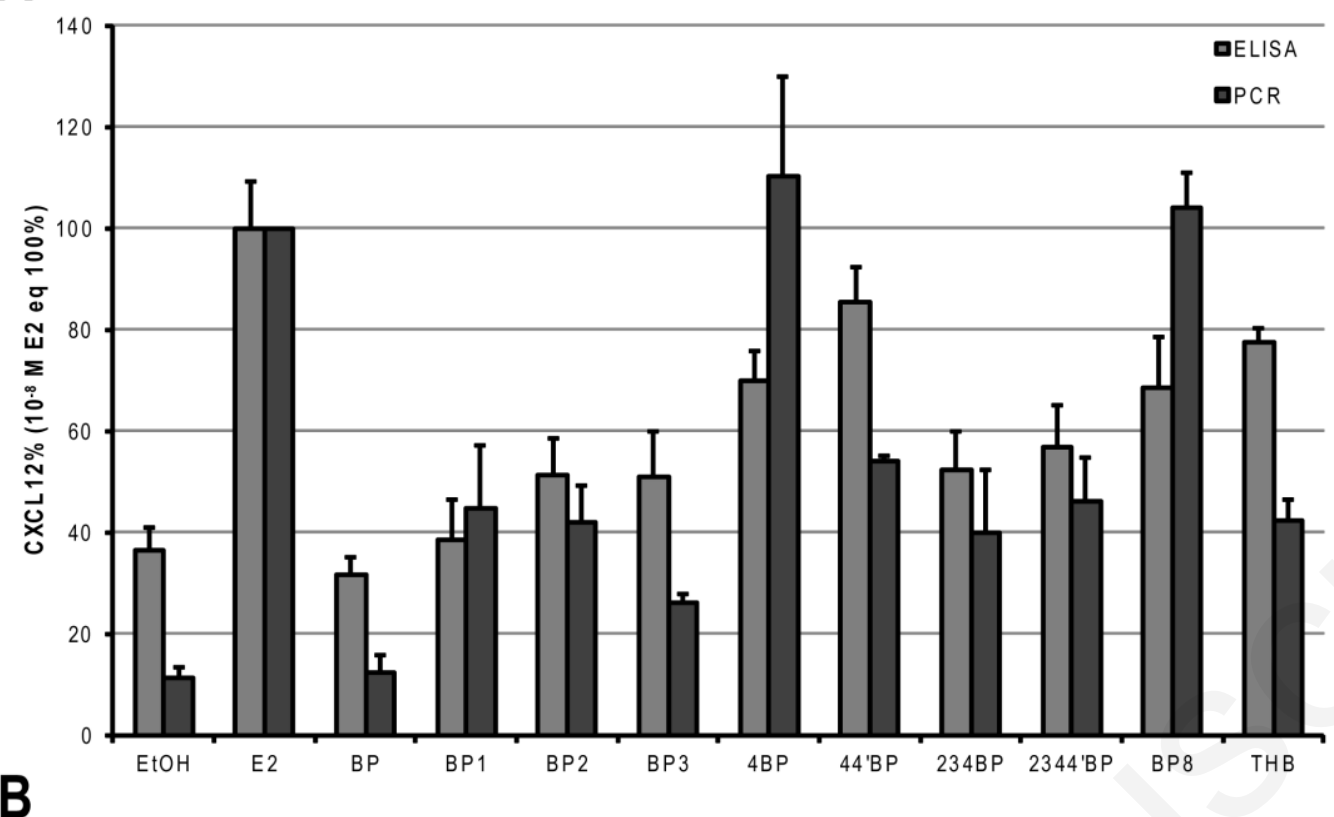

B

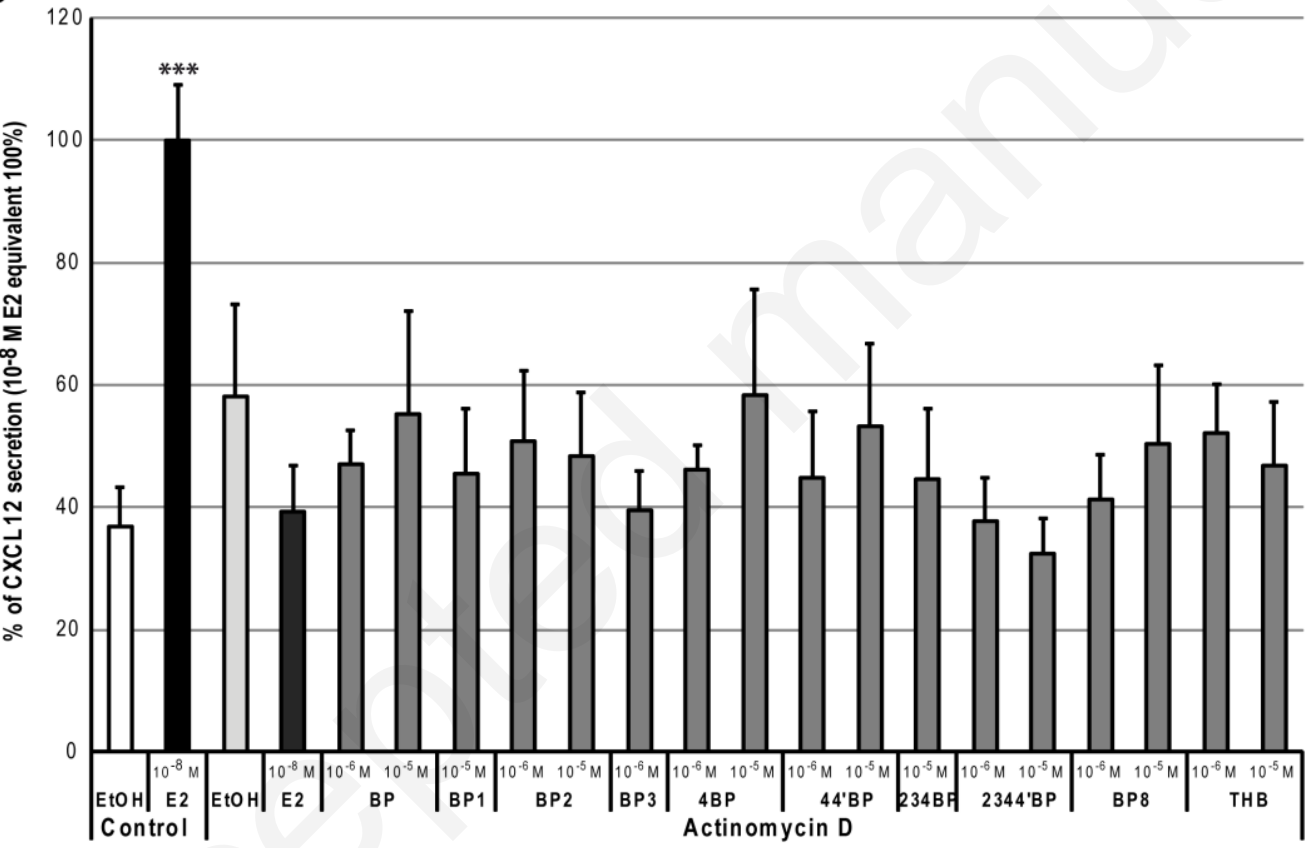

Fig. 5: A) Evolution of CXCL12 secretion and CXCL12 expression measured respectively by ELISA and qPCR after stimulation with $\mathrm{E} 2$ at $10^{-8} \mathrm{M}$ and benzophenones at $10^{-6} \mathrm{M}$. B) CXCL-test performed on cells treated or not with control ethanol, E2 and effective doses of benzophenones with or without actinomycin

D. 


\section{DISCUSSION}

Since decades several methods have been developed for the evaluation and the quantification of endocrine disrupting chemicals, using their ability to induce proliferation, expression of reporter genes or endogenous genes or any other characteristics of these compounds (Kerdivel et al., 2013a; Leusch, 2008; Scholz et al., 2013). These methods used (i) whole animal with uterotrophic test in mouse (Isenhower et al., 1986) or vitellogenin test in fish (Flouriot et al., 1995), (ii) cell-based in vitro assays such as proliferation test (Soto et al., 1986), differentiation test (Habauzit et al., 2014) or reporter assays and (iii) molecular in vitro assay with receptor binding assay (Habauzit et al., 2008). Each of these methods has their own advantages such as integrated response, physiological response, specific response or fast response. Here we have aimed to optimize the CXCL-test in order to increase the number of molecules to be tested in a single assay. We also evidenced the low detection limit of the CXCL-test and that the use of natural endogenous gene expression could be an early indicator of the proliferation capacity of a molecule. This development opens the possibility to use this test as a high throughput assay for estrogenic compounds screening. This method is fast and alternative to animal test in agreement with REACH program (Lombardo et al., 2014a, 2014b). At the moment, one of the main methods used for evaluation of xeno-estrogens properties of chemicals is the ER-positive cell line proliferation test based on Soto et al. work which was originally developed on T47D cell line (Soto et al., 1986). The CXCL-test is a method that allows fast assessment of the estrogen-like action of endocrine disruptors. This test constitutes an alternative for proliferative test (14 hours versus 5 days) of ER-positive cell lines (such as MCF7 or T47D) (Habauzit et al., 2010). This test relied on the ability of estrogens to induce the expression and the secretion of CXCL12 in ER-positive cells which has been demonstrated in many tissues and cancers (Boudot et al., 2014; Roberti et al., 2012). CXCL12 and its two G-coupled receptors CXCR4 and CXCR7 are involved in the proliferation of ER-positive cancer cells (Boudot et al. 2011), and is also a marker of the breast cancer progression (Boudot et al. 2014). Indeed, when breast cancer cell progress they lose the estrogenic sensitivity, the decrease of the local CXCL12 secretion induces EMT and metastasis (Boudot et al., 2014; Roberti et al., 2012). In this article, we proposed key parameters that should be considered for test improvement. First of all, we intended to increase the number of tested molecules at the same time by adapting the method to the 96 well plates. By screening the classical estrogenic compounds E2, EE2 and Gen, the reproducibility of the method was checked with our previously data (Habauzit et al., 2010). Secondly, in order to avoid the intermediate dilution of the supernatant, the number of cells was decreased to 10000 cells per well. The final method greatly decreases 
the time and steps needed for the global evaluation of the estrogenic potency of a large number of compounds. Finally, when compared to the classically used proliferation test, our optimized CXCL-test allows an easier interpretation of the results and the saving of time is really significant even if this test could exhibit a slightly more expensive cost. These kinds of fast and accurate detection methods are clearly important for risk assessment, considering the constant increase of new chemicals released in the environment.

Altogether, these optimized conditions were used for the screening of the benzophenone derivatives that are emerging endocrine disruptors. These molecules are present in some cosmetics and are found in many surface waters around the world with an environmental concentration from $\mathrm{ng} / \mathrm{L}$ to $\mu \mathrm{g} / \mathrm{L}$ (Jurado et al., 2014; Loraine and Pettigrove, 2006; Molins-Delgado et al., 2016). These compounds began to be increasingly studied because of their potential risk for human and wildlife (Kim and Choi, 2014).

All tested BPs exhibit estrogen-like activity with various potencies. Indeed, BP, BP1, BP2, BP3, 234BP and $2344^{\prime} \mathrm{BP}$ showed a weak estrogenic potency even at $10^{-5} \mathrm{M}$. Surprisingly, the BP molecule showed a weak but detectable estrogenic activity in inducing CXCL12 secretion. However our previous docking analysis suggested no direct interaction with ER ligand-binding domain (Kerdivel et al., 2013b). This low estrogenic activity of $\mathrm{BP}$ molecule observed at $10^{-5} \mathrm{M}$ is probably due to its conversion in $4 \mathrm{BP}$ in cell culture (Hayashi et al., 2006; Nakagawa et al., 2000). On the other hand, 4BP, 44'BP, BP8 and THB showed much more potent estrogenic activity inducing a response from $10^{-6} \mathrm{M}$. Among these compounds, 4BP and BP8 were also described as the most potent estrogenic compounds, in regards to previously published results on estrogensensitive reporter assays and on the expression of the CXCL12 gene in MCF7 cell lines (Kerdivel et al., 2013b). The difference in the estrogenic sensitivity is probably due to the ER $\alpha / E R \beta$ ratio which is different in MCF7 and T47D cells. Our previously published data have also evidenced that T47D cells are more sensitive to estrogenic stimulation than MCF7 especially for genistein (Habauzit et al., 2010). Moreover, ER $\beta$ stably expressed in Hela cells (HELN ER $\beta$ assay) exhibited much more sensitivity than ER $\alpha$ for several benzophenones such as BP1, BP2 and THB (Molina-Molina et al., 2008).

Under benzophenone treatments, stimulations of the CXCL12 mRNA expression and protein secretion were nearly identical with a correlation of more than $80 \%$. This was also demonstrated by the actinomycin D treatments, showing that the increase of CXCL12 secretion is only due to the increase of CXCL12 expression and not to an increase of CXCL12 release in the supernatant by BP-induced exocytosis. However, because of the 
duration of treatment (14 hours for secretion and 24 hours for the qPCR) and technique sensitivity, some differences in the amplitude of response were observed. Here we evaluated only the short-term effect of these molecules. However, the benzophenone endocrine activity is currently under question especially about the potential transgenerational effects. For instance, a recent study showed that BP3 has adverse effects in Japanese medaka and some transgenerational disrupting effects in hormonal balance and reproductive function may be noticed when fish were exposure at the level of $\mu \mathrm{g}$ / L to BP3 (Kim et al., 2014).

\section{CONCLUSION}

Today thousand chemicals are currently used in common human life without knowing their endocrine disrupting status. Among the number of methods that have been developed last decades, the CXCL-test promotes a very low detection limit for well-known estrogenic compounds E2 and EE2, and used a natural and untransformed gene that is involved in the proliferation and the migration of the breast cancer cells. In this study, we described the optimization of CXCL-test that permits fast and reliable evaluation of the estrogenic potencies of environmental chemicals. We used this optimized test to evaluate the EDC activity of some benzophenone derivatives. These compounds present in environment in high concentration have an estrogenic activity and constitute a risk for human and wildlife.

\section{Acknowledgements}

Authors are grateful to Dr. Frederic Leusch for its help and advices during the evaluation of this article. This work was supported by funds from the French Ministry of Ecology, Energy and Sustainable Development (PNRPE). We also thank CNRS, INSERM and the University of Rennes 1 for supporting our research.

The authors declare that they have no conflict of interest. 
Boudot, A., Kerdivel, G., Habauzit, D., Eeckhoute, J., Le Dily, F., Flouriot, G., Samson, M., Pakdel, F., 2011. Differential estrogen-regulation of CXCL12 chemokine receptors, CXCR4 and CXCR7, contributes to the growth effect of estrogens in breast cancer cells. PloS One 6, e20898. doi:10.1371/journal.pone.0020898

Boudot, A., Kerdivel, G., Lecomte, S., Flouriot, G., Desille, M., Godey, F., Leveque, J., Tas, P., Le Dréan, Y., Pakdel, F., 2014. COUP-TFI modifies CXCL12 and CXCR4 expression by activating EGF signaling and stimulates breast cancer cell migration. BMC Cancer 14, 407. doi:10.1186/1471-2407-14-407

Flouriot, G., Pakdel, F., Ducouret, B., Valotaire, Y., 1995. Influence of xenobiotics on rainbow trout liver estrogen receptor and vitellogenin gene expression. J. Mol. Endocrinol. 15, 143-151.

Gago-Ferrero, P., Díaz-Cruz, M.S., Barceló, D., 2011. Fast pressurized liquid extraction with in-cell purification and analysis by liquid chromatography tandem mass spectrometry for the determination of UV filters and their degradation products in sediments. Anal. Bioanal. Chem. 400, 2195-2204. doi:10.1007/s00216-011-4951-1

Glace, L., Grygielko, E.T., Boyle, R., Wang, Q., Laping, N.J., Sulpizio, A.C., Bray, J.D., 2009. Estrogeninduced stromal cell-derived factor-1 (SDF-1/Cxc112) expression is repressed by progesterone and by Selective Estrogen Receptor Modulators via estrogen receptor alpha in rat uterine cells and tissues. Steroids 74, 1015-1024. doi:10.1016/j.steroids.2009.07.011

Habauzit, D., Armengaud, J., Roig, B., Chopineau, J., 2008. Determination of estrogen presence in water by SPR using estrogen receptor dimerization. Anal. Bioanal. Chem. 390, 873-883. doi:10.1007/s00216-007$1725-\mathrm{x}$

Habauzit, D., Boudot, A., Kerdivel, G., Flouriot, G., Pakdel, F., 2010. Development and validation of a test for environmental estrogens: Checking xeno-estrogen activity by CXCL12 secretion in BREAST CANCER CELL LINES (CXCL-test). Environ. Toxicol. 25, 495-503. doi:10.1002/tox.20594

Habauzit, D., Chopineau, J., Roig, B., 2007. SPR-based biosensors: a tool for biodetection of hormonal compounds. Anal. Bioanal. Chem. 387, 1215-1223. doi:10.1007/s00216-006-0958-4

Habauzit, D., Ferrière, F., Botherel, N., Flouriot, G., Pakdel, F., Saligaut, C., 2014. Differentiation of PC12 cells expressing estrogen receptor alpha: a new bioassay for endocrine-disrupting chemicals evaluation. Chemosphere 112, 240-247. doi:10.1016/j.chemosphere.2014.03.101

Hall, J.M., Korach, K.S., 2013. Endocrine disrupting chemicals promote the growth of ovarian cancer cells via the ER-CXCL12-CXCR4 signaling axis. Mol. Carcinog. 52, 715-725. doi:10.1002/mc.21913

Hall, J.M., Korach, K.S., 2003. Stromal cell-derived factor 1, a novel target of estrogen receptor action, mediates the mitogenic effects of estradiol in ovarian and breast cancer cells. Mol. Endocrinol. Baltim. Md 17, 792-803. doi:10.1210/me.2002-0438

Hayashi, T., Okamoto, Y., Ueda, K., Kojima, N., 2006. Formation of estrogenic products from benzophenone after exposure to sunlight. Toxicol. Lett. 167, 1-7. doi:10.1016/j.toxlet.2006.08.001

Isenhower, W.D., Newbold, R.R., Cefalo, R.C., Korach, K.S., McLachlan, J.A., 1986. Absence of estrogenic activity in some drugs commonly used during pregnancy. Biol. Res. Pregnancy Perinatol. 7, 6-10.

Jurado, A., Gago-Ferrero, P., Vàzquez-Suné, E., Carrera, J., Pujades, E., Díaz-Cruz, M.S., Barceló, D., 2014. Urban groundwater contamination by residues of UV filters. J. Hazard. Mater. 271, 141-149. doi:10.1016/j.jhazmat.2014.01.036

Kerdivel, G., Habauzit, D., Pakdel, F., 2013a. Assessment and molecular actions of endocrine-disrupting chemicals that interfere with estrogen receptor pathways. Int. J. Endocrinol. 2013, 501851. doi:10.1155/2013/501851

Kerdivel, G., Le Guevel, R., Habauzit, D., Brion, F., Ait-Aissa, S., Pakdel, F., 2013b. Estrogenic potency of benzophenone UV filters in breast cancer cells: proliferative and transcriptional activity substantiated by docking analysis. PloS One 8, e60567. doi:10.1371/journal.pone.0060567

Kim, S., Choi, K., 2014. Occurrences, toxicities, and ecological risks of benzophenone-3, a common component of organic sunscreen products: a mini-review. Environ. Int. 70, 143-157. doi:10.1016/j.envint.2014.05.015

Kim, S., Jung, D., Kho, Y., Choi, K., 2014. Effects of benzophenone-3 exposure on endocrine disruption and reproduction of Japanese medaka (Oryzias latipes)--a two generation exposure study. Aquat. Toxicol. Amst. Neth. 155, 244-252. doi:10.1016/j.aquatox.2014.07.004

Leusch, F., 2008. Tools to Detect Estrogenic Activity in Environmental Waters., Global Water Research Coalition 2008.

Lombardo, A., Roncaglioni, A., Benfenati, E., Nendza, M., Segner, H., Jeram, S., Pauné, E., Schüürmann, G., 2014a. Optimizing the aquatic toxicity assessment under REACH through an integrated testing strategy (ITS). Environ. Res. 135, 156-164. doi:10.1016/j.envres.2014.09.002 
Lombardo, A., Roncaglioni, A., Benfentati, E., Nendza, M., Segner, H., Fernández, A., Kühne, R., Franco, A., Pauné, E., Schüürmann, G., 2014b. Integrated testing strategy (ITS) for bioaccumulation assessment under REACH. Environ. Int. 69, 40-50. doi:10.1016/j.envint.2014.04.005

Loraine, G.A., Pettigrove, M.E., 2006. Seasonal variations in concentrations of pharmaceuticals and personal care products in drinking water and reclaimed wastewater in southern California. Environ. Sci. Technol. 40, 687-695.

Molina-Molina, J.-M., Escande, A., Pillon, A., Gomez, E., Pakdel, F., Cavaillès, V., Olea, N., Aït-Aïssa, S., Balaguer, P., 2008. Profiling of benzophenone derivatives using fish and human estrogen receptorspecific in vitro bioassays. Toxicol. Appl. Pharmacol. 232, 384-395. doi:10.1016/j.taap.2008.07.017

Molins-Delgado, D., Díaz-Cruz, M.S., Barceló, D., 2016. Ecological risk assessment associated to the removal of endocrine-disrupting parabens and benzophenone-4 in wastewater treatment. J. Hazard. Mater. 310, 143-151. doi:10.1016/j.jhazmat.2016.02.030

Nakagawa, Y., Suzuki, T., Tayama, S., 2000. Metabolism and toxicity of benzophenone in isolated rat hepatocytes and estrogenic activity of its metabolites in MCF-7 cells. Toxicology 156, 27-36.

Pattarozzi, A., Gatti, M., Barbieri, F., Würth, R., Porcile, C., Lunardi, G., Ratto, A., Favoni, R., Bajetto, A., Ferrari, A., Florio, T., 2008. 17beta-estradiol promotes breast cancer cell proliferation-inducing stromal cell-derived factor-1-mediated epidermal growth factor receptor transactivation: reversal by gefitinib pretreatment. Mol. Pharmacol. 73, 191-202. doi:10.1124/mol.107.039974

Roberti, M.P., Arriaga, J.M., Bianchini, M., Quintá, H.R., Bravo, A.I., Levy, E.M., Mordoh, J., Barrio, M.M., 2012. Protein expression changes during human triple negative breast cancer cell line progression to lymph node metastasis in a xenografted model in nude mice. Cancer Biol. Ther. 13, 1123-1140. doi:10.4161/cbt.21187

Rodríguez-Gómez, R., Jiménez-Díaz, I., Zafra-Gómez, A., Ballesteros, O., Navalón, A., 2014. A multiresidue method for the determination of selected endocrine disrupting chemicals in human breast milk based on a simple extraction procedure. Talanta 130, 561-570. doi:10.1016/j.talanta.2014.07.047

Scholz, S., Renner, P., Belanger, S.E., Busquet, F., Davi, R., Demeneix, B.A., Denny, J.S., Léonard, M., McMaster, M.E., Villeneuve, D.L., Embry, M.R., 2013. Alternatives to in vivo tests to detect endocrine disrupting chemicals (EDCs) in fish and amphibians--screening for estrogen, androgen and thyroid hormone disruption. Crit. Rev. Toxicol. 43, 45-72. doi:10.3109/10408444.2012.737762

Soto, A.M., Murai, J.T., Siiteri, P.K., Sonnenschein, C., 1986. Control of cell proliferation: evidence for negative control on estrogen-sensitive T47D human breast cancer cells. Cancer Res. 46, 2271-2275.

Soto, A.M., Sonnenschein, C., Chung, K.L., Fernandez, M.F., Olea, N., Serrano, F.O., 1995. The E-SCREEN assay as a tool to identify estrogens: an update on estrogenic environmental pollutants. Environ. Health Perspect. 103 Suppl 7, 113-122.

Tsui, M.M.P., Leung, H.W., Wai, T.-C., Yamashita, N., Taniyasu, S., Liu, W., Lam, P.K.S., Murphy, M.B., 2014. Occurrence, distribution and ecological risk assessment of multiple classes of UV filters in surface waters from different countries. Water Res. 67, 55-65. doi:10.1016/j.watres.2014.09.013

Vela-Soria, F., Ballesteros, O., Zafra-Gómez, A., Ballesteros, L., Navalón, A., 2014. A multiclass method for the analysis of endocrine disrupting chemicals in human urine samples. Sample treatment by dispersive liquid-liquid microextraction. Talanta 129, 209-218. doi:10.1016/j.talanta.2014.05.016

Yoon, K., Kwack, S.J., Kim, H.S., Lee, B.-M., 2014. Estrogenic endocrine-disrupting chemicals: molecular mechanisms of actions on putative human diseases. J. Toxicol. Environ. Health B Crit. Rev. 17, 127174. doi:10.1080/10937404.2014.882194 